
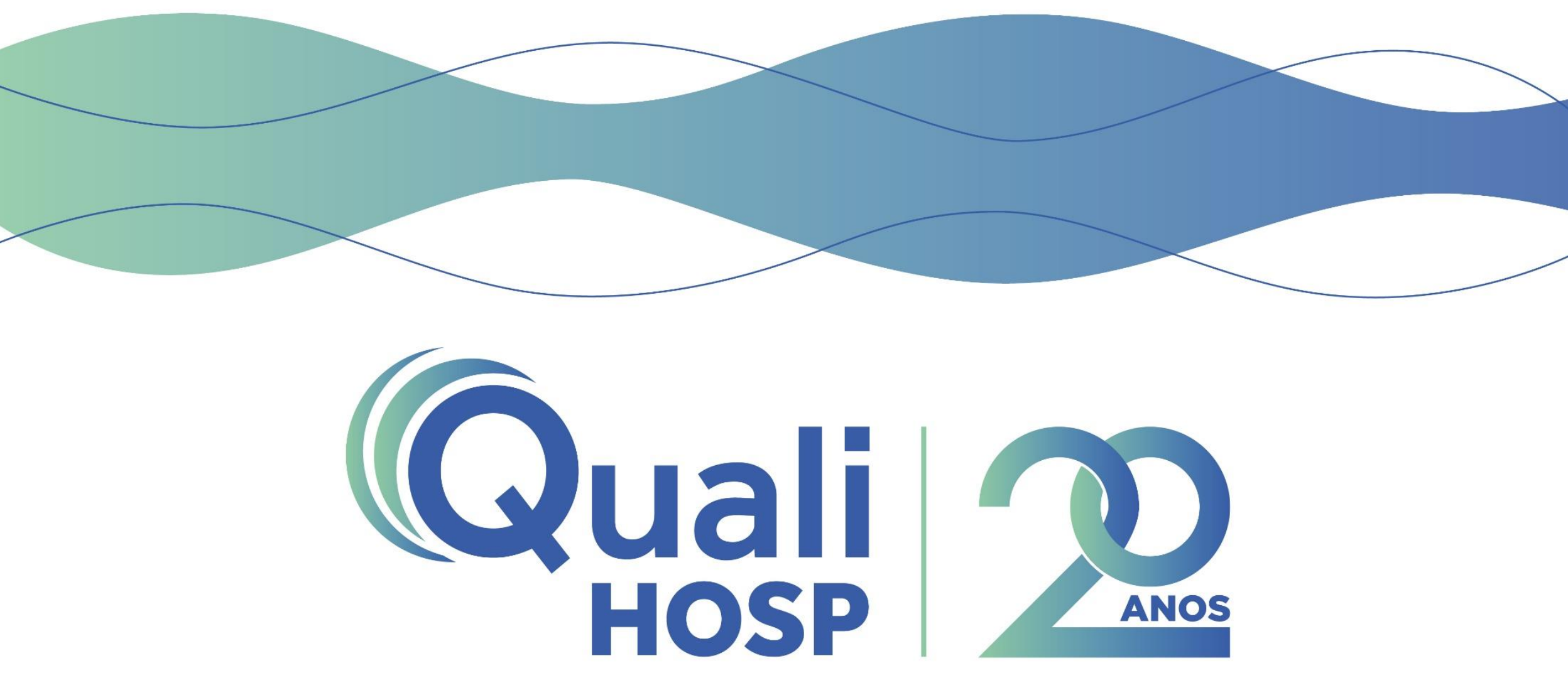

TO ERR IS HUMAN: 20 ANOS EM AÇÃO 


\section{Quali

\section{Alta porcentagem de crianças e adolescentes com ficha espelho vacinal em atraso}

Autor: Mayara Christine Felix de Andrade

Co-autores: Viviane Santana dos Santos, Ernandes Souza Silva, Alzira Claudia Pereira Castro, Priscila Toledo Vida Lopes. 


\section{Porcentagem de crianças e adolescentes com ficha espelho vacinal em atraso}

- Março 2018- SPDM assume a gestão da UBS Rio Pequeno

Área de abrangência: 22.185 pessoas (censo 2010).

Unidade tradicional

- Contrato de gestão SPDM-PMSP= índice de cobertura vacinal em dia > 90\% em crianças menores de 1 ano

Diagnóstico situacional de carteiras vacinais em dia- Março 2018:

\begin{tabular}{|c|c|c|c|}
\hline Mês & 0-12 meses & 1-4anos & 5 a 15 anos \\
\hline Março & $63,72 \%$ & $58,33 \%$ & $52,7 \%$ \\
\hline
\end{tabular}




\section{Matriz de Priorização/GUT- PDSA UBS Rio Pequeno}

\begin{tabular}{|c|l|c|c|c|c|c|}
\hline $\begin{array}{c}\text { I.D. } \\
\text { Causa }\end{array}$ & \multicolumn{1}{|c|}{ Problemas } & G & $\mathbf{U}$ & $\mathbf{T}$ & $\begin{array}{c}\text { Total } \\
\text { (GxUxT) }\end{array}$ & Priorização \\
\hline P1 & Organização da rede de frio fora do padrão & 5 & 5 & 5 & 125 & 1 1o \\
\hline P2 & Ausência de impressos de rotina da sala de vacina & 5 & 4 & 5 & 100 & 20 \\
\hline P3 & Cadastro de doses desatualizado no sistema SIGA & 4 & 3 & 4 & 48 & 3o \\
\hline P4 & Arquivo sem organização conforme protocolo & 3 & 2 & 2 & 12 & 40 \\
\hline P5 & Excesso de ficha espelho & 2 & 2 & 2 & 8 & 5o \\
\hline
\end{tabular}




\section{W2H- UBS RIO PEQUENO}

\section{Quali

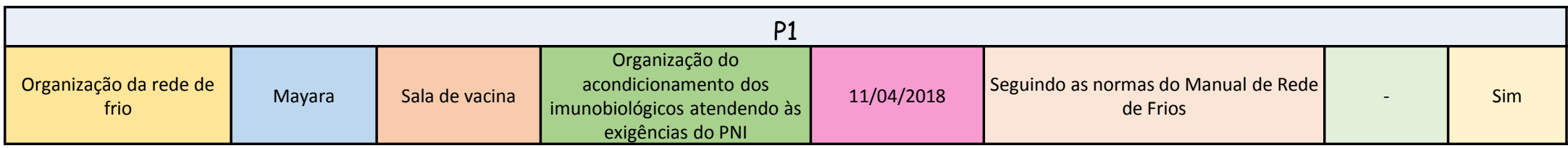

\begin{tabular}{|c|c|c|c|c|c|c|}
\hline & & & P2 & & & \\
\hline $\begin{array}{c}\text { Implantacao de impressos } \\
\text { preconizados }\end{array}$ & Mayara & Sala de vacina & $\begin{array}{c}\text { Para controle e organização do } \\
\text { número de doses aplicadas por } \\
\text { lote e faixa etária }\end{array}$ & $09 / a b r$ & $\begin{array}{c}\text { Disponibilização do impresso e } \\
\text { capactação da equipe para a utilização } \\
\text { do mesmo }\end{array}$ & Sim \\
\hline
\end{tabular}

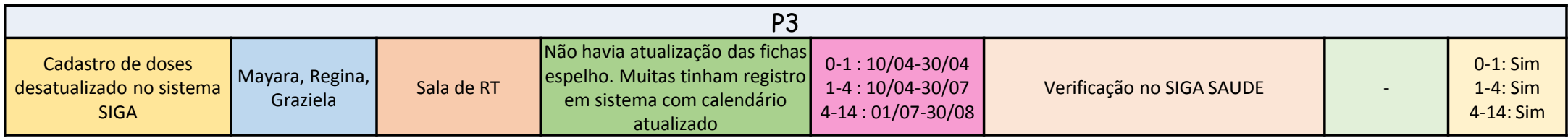

\begin{tabular}{|c|c|c|c|c|c|c|c|}
\hline \multicolumn{8}{|c|}{ P4 } \\
\hline $\begin{array}{c}\text { Arquivo sem organização e } \\
\text { preenchimento conforme } \\
\text { protocolo }\end{array}$ & Mayara & Sala de RT & $\begin{array}{c}\text { Organização dos arquivos do } \\
\text { setor }\end{array}$ & $10 / 04-01 / 05$ & $\begin{array}{l}\text { Implantação de pastas de organização de } \\
\text { acordo com faixa etária }\end{array}$ & $\mathrm{R} \$ 287,00$ & Sim \\
\hline $\begin{array}{l}\text { Padronização do } \\
\text { preenchimento e } \\
\text { organização }\end{array}$ & Mayara & Sala de RT & $\begin{array}{l}\text { Padronizar o preenchimento e } \\
\text { organizar a forma de arquivar }\end{array}$ & $10 / 04-01 / 06$ & $\begin{array}{l}\text { Treinamento teórico e prático das } \\
\text { colaboradoras }\end{array}$ & - & Sim \\
\hline
\end{tabular}

\begin{tabular}{|c|c|c|c|c|c|c|}
\hline \multicolumn{7}{|c|}{ P5 } \\
\hline $\begin{array}{l}\text { Análise das ficha espelho } \\
\text { existentes na unidade }\end{array}$ & Mayara Andrade & $\begin{array}{c}\text { Sala de } \\
\text { Enfermagem }\end{array}$ & $\begin{array}{l}\text { Organizar o arquivo conforme } \\
\text { orientação do manual de } \\
\text { normas e rotinas do Ministério } \\
\text { da Saúde, adotado pela SPDM } \\
\text { no território. }\end{array}$ & $10 / 04-30 / 08 / 2018$ & $\begin{array}{l}\text { Separando as fichas por faixa etária e } \\
\text { área de abrangência }\end{array}$ & Sim \\
\hline
\end{tabular}




\section{Quali HOSP}

- Necessidade da elaboração e implantação de um sistema de controle de fichas espelho na unidade, planilha com o registro de todas as fichas da unidade, com data de retorno e situação vacinal.

\begin{tabular}{|l|c|c|c|c|}
\hline \multicolumn{1}{|c|}{ Nome } & D.N & SUS & $\begin{array}{c}\text { Situação } \\
\text { vacinal }\end{array}$ & Retorno \\
\hline A.C.B & $20 / 09 / 18$ & 835503014832552 & em dia & $04 / 03 / 2019$ \\
\hline A.N.M & $19 / 11 / 18$ & 700000620280808 & em dia & $22 / 03 / 2019$ \\
\hline A.E.A & $06 / 07 / 18$ & 835503013159080 & em dia & $06 / 03 / 2019$ \\
\hline A.C.S.M.B & $15 / 07 / 2018$ & 835503013647034 & mês anterior & $22 / 02 / 2019$ \\
\hline A.M.G & $04 / 10 / 2018$ & 835503014245374 & em dia & $07 / 03 / 2019$ \\
\hline A.A.T & $24 / 10 / 2018$ & 835503015446133 & em dia & $15 / 03 / 2019$ \\
\hline A.H.C.L & $05 / 05 / 2018$ & 700900958581394 & em dia & $05 / 05 / 2019$ \\
\hline A.S.R & $02 / 06 / 2018$ & 835503013205651 & em dia & $02 / 03 / 2019$ \\
\hline B.F.G & $23 / 02 / 2018$ & 835503011149371 & mês anterior & $23 / 02 / 2019$ \\
\hline R.S.T & $01 / 01 / 2018$ & 835503006430084 & em dia & $01 / 04 / 2019$ \\
\hline B.R.T.O & $04 / 05 / 2018$ & 835503012671780 & em dia & $04 / 05 / 2019$ \\
\hline L.L.N & $14 / 01 / 2018$ & 835503006814079 & em dia & $14 / 04 / 2019$ \\
\hline B.T.A & $24 / 01 / 2018$ & 835503008260070 & atrasado & $24 / 01 / 2019$ \\
\hline B.A.F & $23 / 10 / 2018$ & 835503145418709 & em dia & $25 / 03 / 2019$ \\
\hline B.N.R & $10 / 03 / 2018$ & 835503010136136 & em dia & $10 / 03 / 2019$ \\
\hline B.C.G & $09 / 12 / 2018$ & 835503016213582 & em dia & $15 / 03 / 2019$ \\
\hline
\end{tabular}

Pasta mês vigente

Pasta mês anterior

Pasta de faltosos

(atentar para D.N)

Pasta de retorno nos

próximos meses

Arquivo

Busca ativa através de contato telefônico

Busca ativa através de visita domiciliar

Serviço social

Intersetorialidade - PSE 


\section{RESULTADOS}

Tecnologia + gestão + engajamento da equipe

$=$

Resultados positivos!

\begin{tabular}{|c|c|c|c|}
\hline Mês & $0-12$ meses & $1-4 a n o s$ & 5 a 15 anos \\
\hline Março & $63,72 \%$ & $58,33 \%$ & $52,7 \%$ \\
\hline Abril & $97,01 \%$ & $83,89 \%$ & $52,7 \%$ \\
\hline Maio & $97,76 \%$ & $93,00 \%$ & $52,7 \%$ \\
\hline Junho & $99,21 \%$ & $94,19 \%$ & $72,3 \%$ \\
\hline Julho & $96,72 \%$ & $92,87 \%$ & $71,0 \%$ \\
\hline Agosto & $100,00 \%$ & $97,40 \%$ & $74,7 \%$ \\
\hline Setembro & $99,20 \%$ & $97,39 \%$ & $79,7 \%$ \\
\hline Outubro & $100,00 \%$ & $98,26 \%$ & $79,0 \%$ \\
\hline Novembro & $100,00 \%$ & $98,69 \%$ & $79,7 \%$ \\
\hline Dezembro & $100,00 \%$ & $93,20 \%$ & $79,4 \%$ \\
\hline Janeiro & $100,00 \%$ & $96,80 \%$ & $79,8 \%$ \\
\hline Fevereiro & $100,00 \%$ & $96,22 \%$ & $80,9 \%$ \\
\hline
\end{tabular}

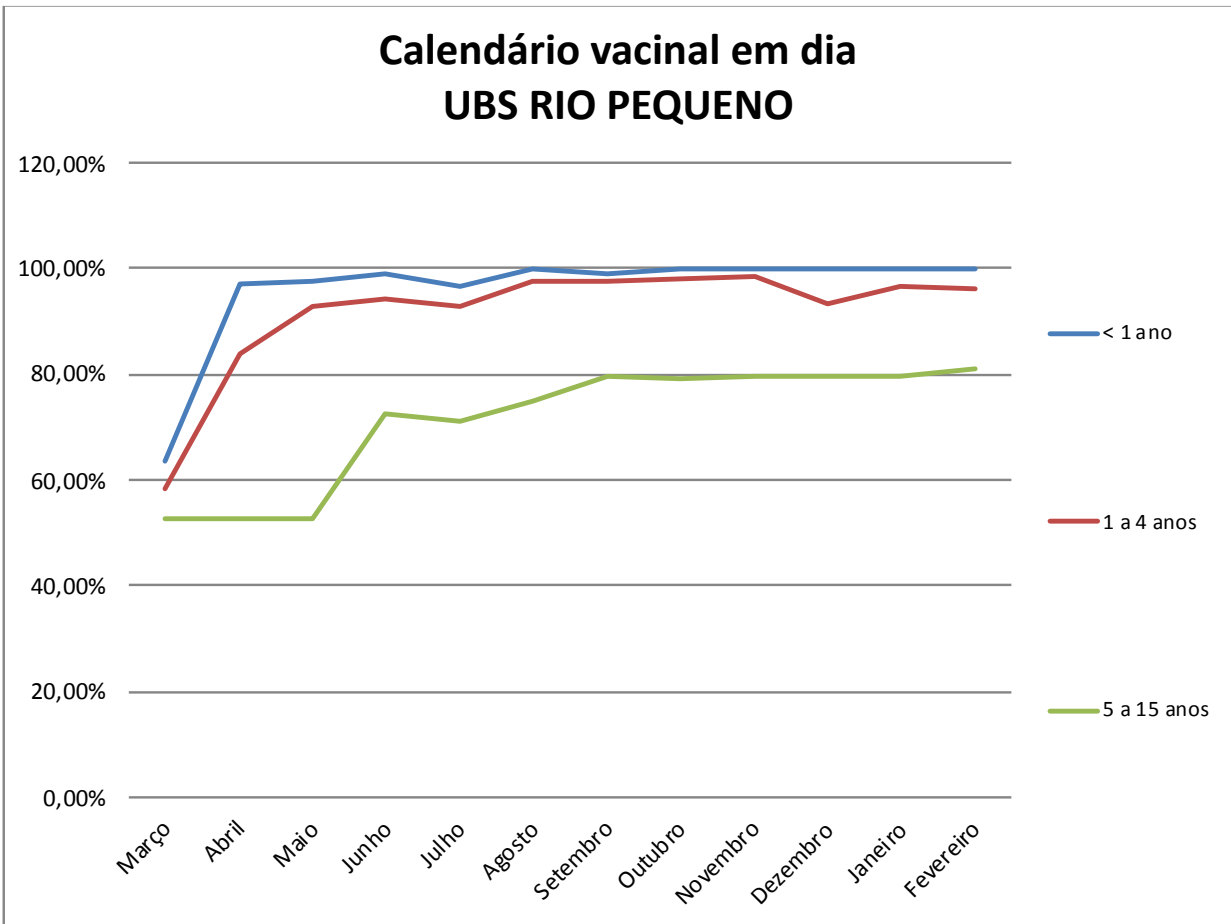




\section{Conclusão}

- Tempo de ação: 6 meses

- Monitorização: contínua

- Custo: $\mathrm{R} \$ 287,00$

Atualmente enfrentamos um paradigma onde a vacinação passa a ser questionada através da propagação de informações erradas, associada a ausência de sensibilização dos responsáveis e diminuição dos surtos de doenças que poderiam ser prevenidas, reduzindo os índices de cobertura vacinal.

Neste contexto, a gestão das fichas espelho é fundamental para aprimorar a busca ativa de crianças em atraso vacinal. 


\section{Quali HOSP}

\section{"Uma pessoa inteligente resolve um problema, um sábio previne" Albert Einstein}

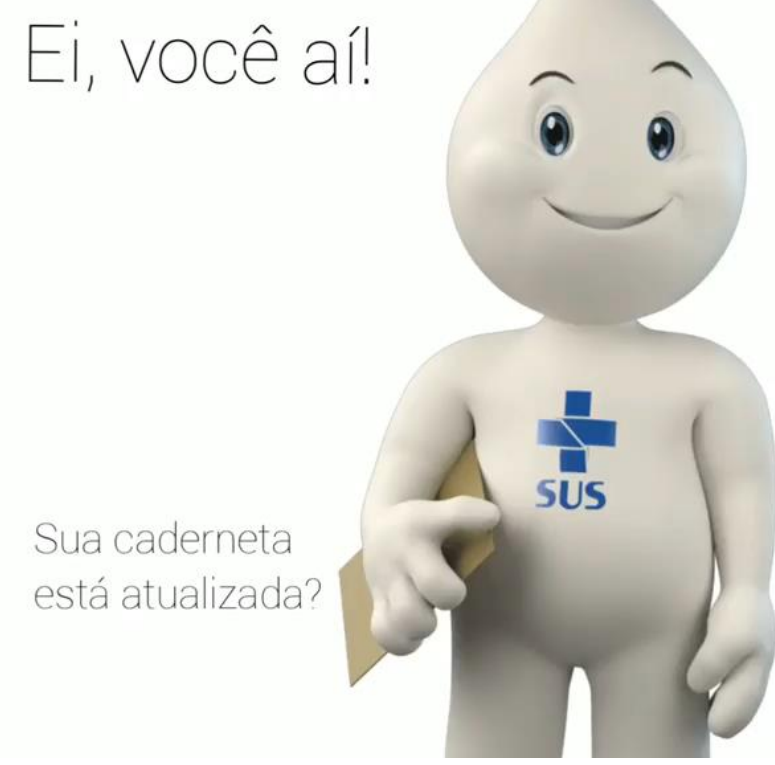

Obrigada!

mayara.andrade@butanta.spdm.org.br 